\title{
The added value of the harmonisation and consistency of laboratories' accreditation to the development of the global market
}

\author{
Álvaro Ribeiro ${ }^{1}$, Jeff Gust ${ }^{2}$, António Vilhena ${ }^{1}$, John Wilson ${ }^{3}$ \\ ${ }^{1}$ National Laboratory for Civil Engineering, Av. do Brasil 101, 1700-066 Lisbon, Portugal \\ 2 Fluke, Everett, WA, United Satetes of America \\ ${ }^{3}$ National Laboratory Association, Pretoria, South Africa
}

\begin{abstract}
Laboratories are the largest group of stakeholders of the International Organization for Laboratory Accreditation (ILAC). The impact of laboratory activities as independent entities that ensure the safety and quality of products and services is growing and becoming a key issue in many fields. New challenges of globalisation, international trade, technological developments, and increasing expectations of citizens and consumers require a robust implementation of accreditation to promote the fair competition and sustainability of laboratories. For this purpose, the harmonization and consistency of accreditation is a major task that can be achieved through the cooperation of all stakeholders. The ILAC Laboratory Committee has conducted a survey to evaluate the present state of harmonization of accreditation activities. The main results are presented in this paper, and some recommendations for future activity are given at the end.
\end{abstract}

\section{Section: RESEARCH PAPER}

Keywords: accreditation; laboratory; conformity assessment; testing

Citation: Alvaro Ribeiro, Jeff Gust, Antonio Vilhena, John Wilson, Added value of harmonisation and consistency of laboratories, Acta IMEKO, vol. 9, no. 1, article 8, March 2020, identifier: IMEKO-ACTA-09 (2020)-01-08

Editor: Lorenzo Ciani, University of Florence, Italy

Received November 25, 2019; In final form February 6, 2020; Published March 2020

Copyright: This is an open-access article distributed under the terms of the Creative Commons Attribution 3.0 License, which permits unrestricted use, distribution, and reproduction in any medium, provided the original author and source are credited.

Corresponding author: Álvaro Ribeiro, e-mail: asribeiro@Inec.pt

\section{INTRODUCTION}

There are many reasons why it is important to understand the relevance of accreditation for the economy. One of the most important reasons is that global markets require a growing level of confidence in goods and services. Trade operations are supported by trust in the quality of goods and services provided by suppliers and agents of the transactions (namely, buyers and sellers) [1].

To provide the assurance of goods and services, a quality control infrastructure is needed, bringing added value to citizens and consumers through the development and use of tools able to fulfil the expectations of safety and quality of life. Quality infrastructure is 'the system comprising the organisations (public and private) together with the policies, relevant legal and regulatory framework, and practices needed to support and enhance the quality, safety and environmental soundness of goods, services and processes' [2].
According to the "Bureau International des Pois et Mesures" (BIPM) [2], 'the quality infrastructure is required for the effective operation of domestic markets, and its international recognition is important to enable access to foreign markets. It is a critical element in promoting and sustaining economic development, as well as environmental and social wellbeing', considering that it relies on five domains:

1) metrology;

2) standardisation;

3) accreditation;

4) conformity assessment; and

5) market surveillance in regulated areas.

The relationship between conformity assessment and accreditation significantly impacts the global economy in that conformity assessment ensures that suppliers consistently meet industry standards and therefore can be relied upon, and accreditation serves as a reinforcement of conformity assessment using external entities (National Accreditation Bodies [NABs]). 


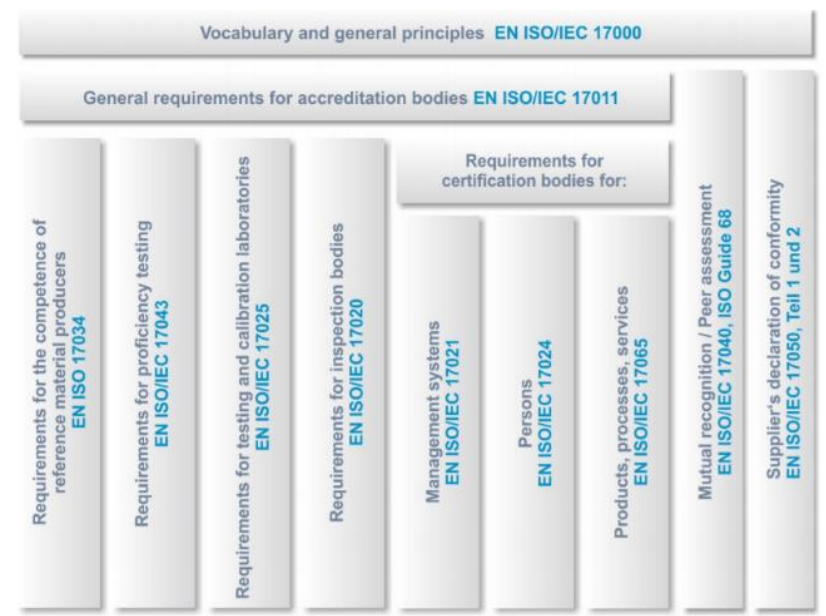

Figure 1. ISO Casco Toolbox (Source: ISO).

The NABs are able to provide an independent way to validate the competence of Conformity Assessment Bodies (CABs), with services such as calibration, testing, inspection, and certification.

The accreditation of CABs is implemented by using system standards that allow, at the international level, the recognition of conformity assessment providers' competence.

For laboratories, ISO/IEC 17025 [3] is the reference, and in the case of inspection bodies, ISO/IEC 17020 [4] supports the accreditation. The framework of these standards is called the ISO Casco toolbox (Figure 1).

The recent revision of ISO/IEC 17025 introduced relevant changes [5], [6], namely an update to the vocabulary, a new structure harmonised with related system standards (e.g. ISO 9000 and others), the concept of impartiality, risk-based thinking, a process-based approach, a higher focus on clients, an interpretation of and requirements for sampling activities, the implementation of decision rules associated with statements of conformance, and a flexible structure for organisations considering the digital transition.

The new structure of the standard modified the previous version published in 2005, which separated the requirement for the laboratory management and technical domains, introducing an approach that considers a composition of five main sections, related to general requirements (focused on impartiality and confidentiality); structural requirements related to the model type of organisations and the way that develop the support for the management system; the resources and processes provided in order to fulfil the requirements for the implementation of the

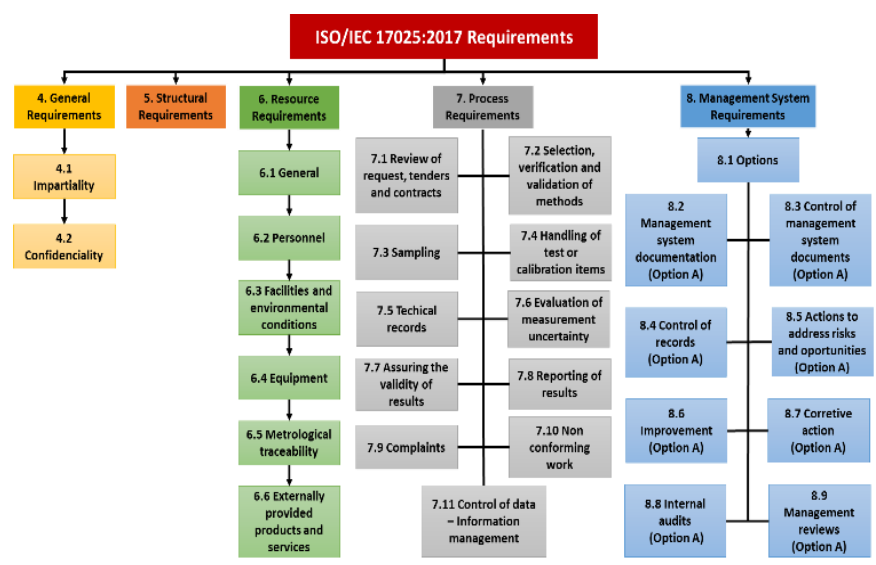

Figure 2. ISO/IEC 17025:2017 requirements. management system; and the requirements oriented to promote the harmonisation with related management systems based on other schemes (e.g. ISO 9001). This structure is briefly presented in Figure 2.

\section{NEW TRENDS}

Today, laboratories face the same challenges as many organisations, overwhelmed by the growing development of technologies, products, materials, and services, which creates new expectations that require innovation as a new tool applied to conformity assessment. The dynamic and sometimes unpredictable world of today, described by the acronym VUCA (Volatility, Uncertainty, Complexity, and Ambiguity) [7], requires leadership, vision, and knowledge to face daily shifts in economy, trade, and international relations.

The increasing velocity of change of technologies through innovation is becoming overwhelming, requiring action upon a future that remains unclear. To prepare strategies, organisations need reliable information about the emerging technology trends in order to provide solutions for a new world of people's expectations [8].

This development is strongly related to the so-called digital transformation, which is in the spotlight of government strategies worldwide. At the European level, the Digital Single Market (DSM) designates the strategy of the European Commission for the best possible access to the online world for individuals and businesses [9] (see Figure 3), expected to have a huge impact on economic growth, boosting jobs, competition, investment, and innovation [10].

To achieve goals related to the digital economy, the smart cities concept [10]; a data-driven society; a reshaping of communication and businesses through 5G; artificial intelligence; and many other challenges, laboratories need to be involved in the digital transition and need to be able to adapt to many daily changes that happen. Urban development and smart cities are key concepts for the understanding of the relations to be established between digital technology, disruptive innovation, and society [11], [12].

To understand and to foresee the impact and development of expected world transformations, specifically in relation to economic models, a global perspective of the trends and the catalysts becomes a key issue [13] for developing strategies for science and technology, which are the support for conformity assessments performed by laboratories.

In this new framework, ISO/IEC 17025 brought to the scene the tools to allow laoratories to create the right conditions to develop management systems and to promote conformity assessments fulfilling the growing expectations of future markets and society. However, the nature of laboratories will have to

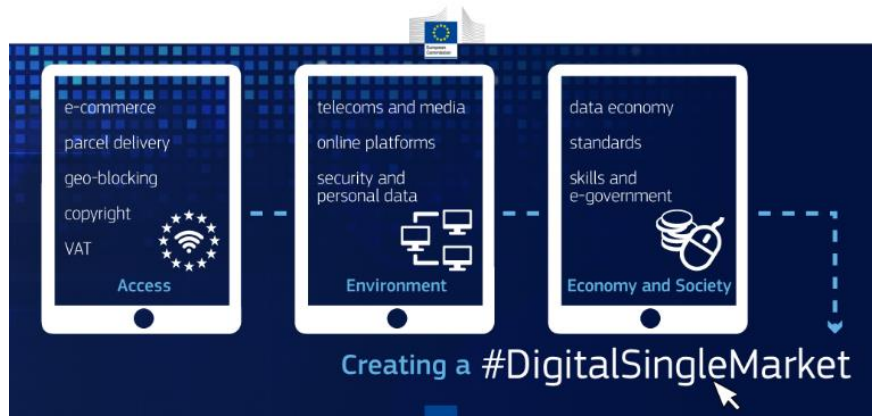

Figure 3. The EU Digital Single Market Strategy [6]. 
adapt to the dynamic nature of the changes, which will require flexibility, responsibility, knowledge (scientific and technical) with higher levels of specialisation and competence in new fields (e.g. data science; data management; artificial intelligence; nano and bio materials; large sensor networks using big data approaches; and quantum computing).

\section{ILAC FORUM AND THE ROLE OF THE ILAC LABORATORY COMMITTEE}

The International Laboratory Accreditation Cooperation (ILAC) was created in 1977 in Copenhagen 'with the aim of developing international cooperation for facilitating trade by promotion of the acceptance of accredited test and calibration results' [14] as the international organisation for accreditation. It includes the accreditation bodies operating in accordance with ISO/IEC 17011, able to support the accreditation of entities such as CABs (using ISO/IEC 17025 [3]), medical laboratories (using ISO 15189 [15]), and inspection bodies (using ISO/IEC 17020 [4]).

The main added value is given by the Mutual Recognition Arrangement (ILAC MRA) [16]; the evolution of accreditation of $\mathrm{CABs}$ in recent years (Figure 4) shows an increasing interest in accreditation and in the ILAC MRA as a way that these entities found to stand out from competitors in the global market.

This mutual recognition gives a unique approach that allows the recognition of the competence of laboratory activity providers from the signatory countries, based on mutual evaluation and acceptance of the national laboratory accreditation systems. The global network of services relies on this system, which expects that they can assure safety and quality of life for citizens and consumers by Testing, Inspection, and Certification (TIC).

The TIC sector market is a large contributor to the economy (see Figure 5), as mentioned in [17]: 'It provides greater consumer protection, safer products and industrial installations, reduces compliance costs for [small- and medium-sized enterprises] SMEs and increases brand reputations and consumers' trust and confidence in a product by ensuring that products, infrastructures and processes meet the required standards and regulations in terms of quality, health and safety, environmental protection and social responsibility and can, therefore, also be a facilitator to international trade'.

According to ILAC, in 2019, almost 80,000 laboratories, 11,000 inspection bodies and over 450 proficiency testing providers were accredited

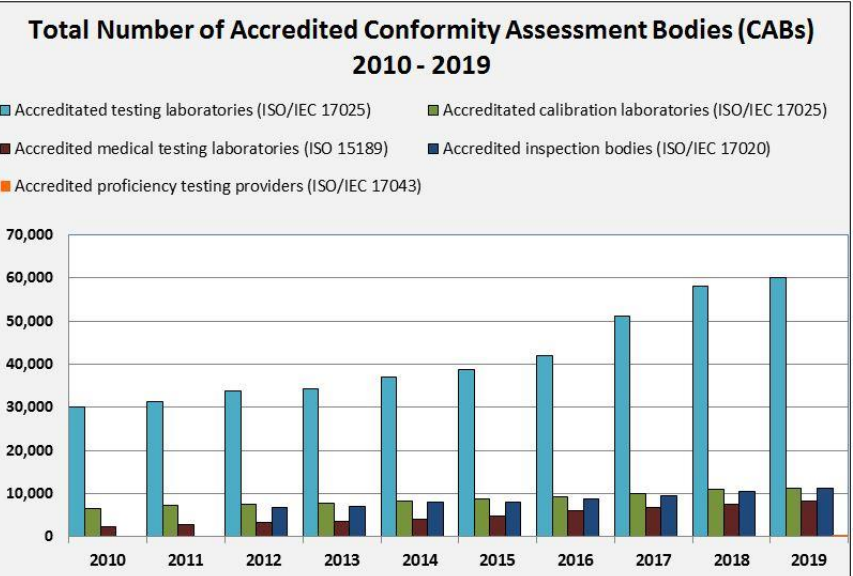

Figure 4. Evolution of accredited CABs worldwide (2010-2019) (Source: https://ilac.org/about-ilac/facts-and-figures).

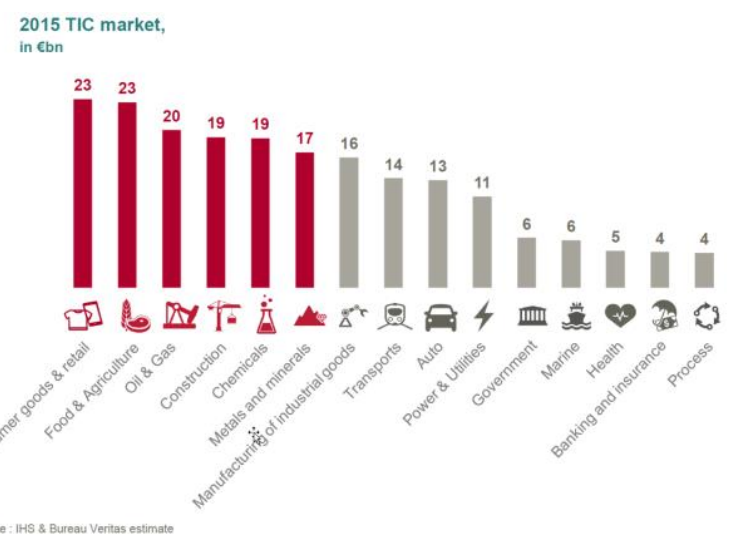

Figure 5. 2015 TIC market (Source: SGS Report).

by ILAC MRA Signatories'. As these numbers show, laboratories have a special role as stakeholders in the ILAC organisation; this role is also recognised with the Laboratory Committee (ILAC LC) in ILAC's structure, which provides a platform for interaction with the laboratory community.

\section{CONCERNS, EXPECTATIONS, AND CHALLENGES OF LABORATORIES: THE 2017 INTERNATIONAL SURVEY}

\subsection{Framework}

As described above, accreditation is essential for modern trade, which requires harmonisation and consistency in the application of its rules worldwide to have a fair and balanced competition. However, in some circumstances, different practices are found at national and regional levels.

To support the development of an ILAC strategy, ILAC LC decided in 2017 to develop an international survey on the harmonisation and consistency of accreditation in order to provide a global view of the concerns, expectations, and challenges of laboratories and CABs, between May and June 2017.

The main conditions to measure the impact of the survey were [18]:

- the number of replies should be statistical relevant;

- ideally, geographical representation should be by countries and by regions;

- it should cover a wide range of activities;

- it should represent a range of small, medium, and large companies and institutions;

- it should cover a range of small to large numbers of accreditation parameters (both testing methods and calibration parameters); and

- $\quad$ it should capture respondents' experience regarding the accreditation process.

The target was to obtain responses from at least 25 countries and 4 continents. 421 responses from 35 countries and the economies of 5 continents were received [18] (Figure 6) from an estimated sample of 1500 laboratories questioned.

The answers received allowed for an analysis divided into three parts:

1) the characterisation and validation of the sample of participants;

2) an accreditation performance analysis; and

3) an analysis of satisfaction regarding the services provided by NABs and an improvement analysis. 


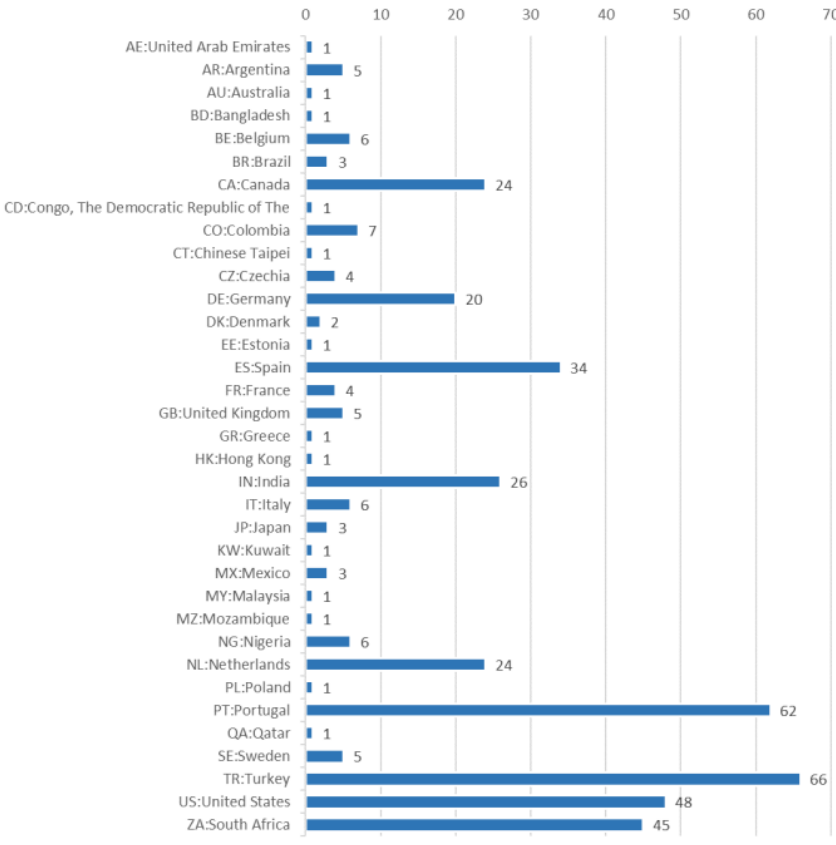

Figure 6. Laboratories by location of main office [18].

Results are presented in an ILAC LC report [18] and include an analysis of the following issues identified by stakeholders of ILAC LC regarding the lack of consistency observed: scope definition; cycle and frequency of assessment; quality of assessment; translation barriers; non-uniform interpretation of ISO 17025 at the national level by accreditation bodies; accreditation body policies; use of PT/ILC and similar quality control tools in assessment; and lack of recognition of ILAC MRA. In the next sections, highlights of those results are presented.

\subsection{Characterisation of laboratories}

A critical issue regarding the development of the survey was how the sampling of the participating laboratories would represent the whole community and their activities. The distribution of laboratories by activities showed that a large spectrum of domains was included, although there was higher participation in some fields, namely agro-food, environment and metrology (Figure 7).

A target for this survey was also to have entities with different perspectives and experience levels regarding the length of accreditation. The answers (Figure 8) show a higher number of responses from laboratories with more years of accreditation. The relatively higher rate of responses from laboratories with long-established accreditation indicates a keen interest in the issues explored in the survey.

Another main topic that was intended to be evaluated was the application of flexible accreditation [19] in testing and calibration contexts, because it is one of the differentiation elements pointed out by the community of laboratories as having different approaches in different countries and economies. The laboratories' answers allowed for verification that at the end of 2017 , only $32 \%$ of test laboratories and $14 \%$ of calibration laboratories have flexible accreditation scopes. Some entities replied that such a scope would not be applicable in their case $(18 \%$ of the test laboratories and $37 \%$ of the calibration laboratories). A more detailed analysis of the 'not applicable' answer shows, in some cases, a lack of awareness of this concept. The comments received show that in some countries and

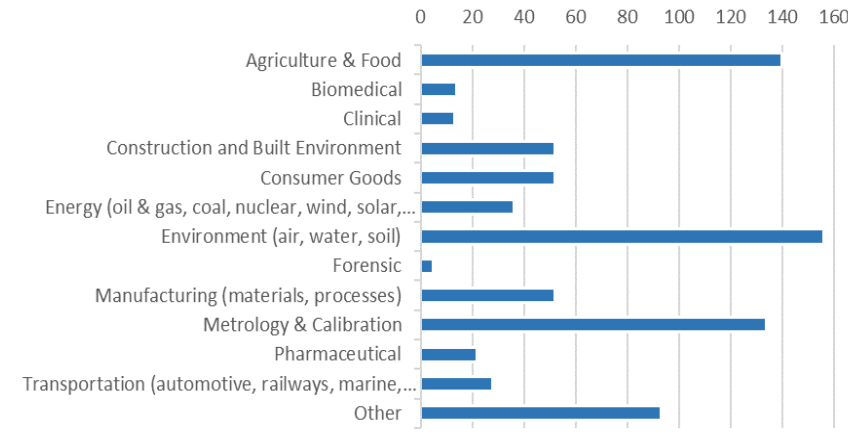

Figure 7. Replies by types of activities [18].

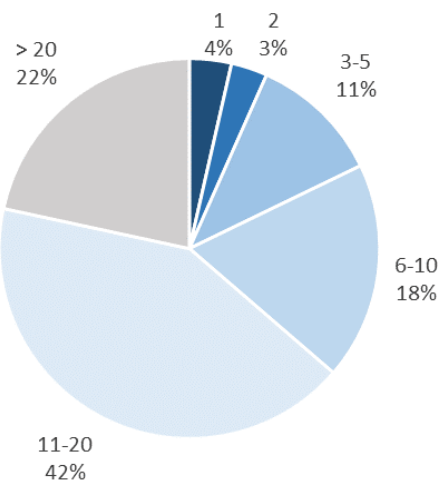

Figure 8. Distribution of responses by years of accreditation [18].

economies, a flexible scope has not yet been implemented, and in the case of calibration, some countries and economies apply it (as semi-flexible) and others do not allow it. This promotes a distortion on the market affecting competitiveness, and in some cases, accreditation bodies do not provide information or promote this possibility.

\subsection{Evaluation of the performance of accreditation bodies}

Another relevant feature of the survey was to develop a performance analysis of accreditation bodies considering the main conditions for accreditation, namely the time it takes to get accreditation, use of extra requirements for accreditation, cooperation with stakeholders, impact of quality control tools, surveillance time interval, and cycle of accreditation.

\subsubsection{Cycle and frequency of assessment}

A set of survey questions addressing the cycle and frequency of assessment was prepared. It was intended to evaluate how these two aspects, which are very relevant to the competitiveness of laboratories, are applied in distinct countries and economies.

The average duration of accreditation cycles varies from 12 months to more than 60 months (Figure 9). In $54 \%$ of the countries and economies, the average duration of the accreditation cycles is equal to or greater than 48 months. Of the remaining countries and economies, $40 \%$ have an average accreditation cycle of 24 months or less.

The average surveillance time interval between audits for main laboratories is mostly 12 months. The main criticism noted from the comments is that many laboratories consider an interval of 12 months between audits to be 'very small' and that the significant repetitive effort securing ongoing accreditation does not contribute real value to the laboratory's activity.

One of the concerns that laboratories have in common is that quality control tools, such as proficiency testing [20], often have 


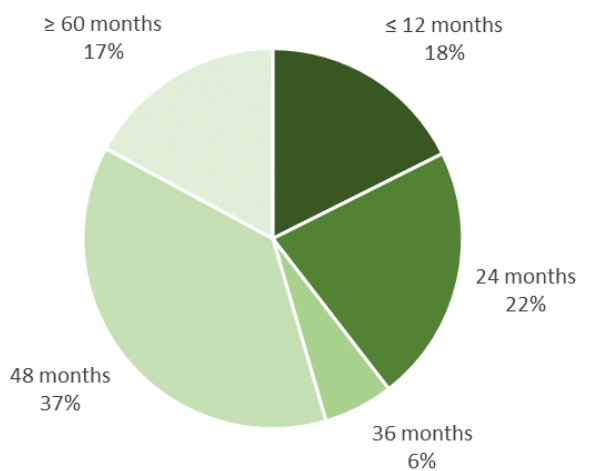

$6 \%$

Figure 9. Distribution by cycle of accreditation [18].

no impact on the external evaluation programs. In fact, only 20 $\%$ of the laboratories experienced a reduction of the assessment effort when previous audits demonstrated that quality control tools were applied with success.

\subsubsection{The performance of accreditation bodies}

Another major concern about the competitiveness of laboratories in the market is the time it takes to get accreditation. $80 \%$ of the laboratories surveyed obtained their accreditation in 12 months or less. On the other hand, $6 \%$ of the laboratories took more than two years to become accredited.

An obstacle to competitiveness and equality in international markets is the existence of accreditation body guides that contain extra national requirements beyond the requirements of the accreditation standards, which may also lead to difficulties in the ILAC MRA process. Often, the laboratories are not consulted in the development of these accreditation body guides. Over half the laboratories $(61 \%)$ responded that their accreditation body has such guides. Again, the results show a wide variety of situations. National (standards) interpretation guides are often not supported by dialogue with stakeholders; $21 \%$ of the participating laboratories answered that the guides are approved without stakeholder participation. Only $29 \%$ answered that their accreditation body develops guides with the agreement/participation of the laboratory stakeholders.

The results also show concerns regarding the introduction of extra requirements by accreditation bodies outside the requirements of the accreditation standards. Over half the laboratories that reported that their accreditation body has national interpretation guides for the reference accreditation standard said that those guides establish extra requirements that are not supported by that standard.

Less than half of the laboratories $(46 \%)$ reported that they are invited to participate in the definition of national strategies for accreditation. For those entities that do participate in the definition of the national accreditation strategy, they are generally involved at lower levels (participation in committees and meetings), with less than $5 \%$ participating at management or director level, as is the case with accreditation bodies (Figure 10).

\subsubsection{Satisfaction of the laboratories and improvement areas}

The final section of the survey aimed to establish a procedure for evaluating the degree of satisfaction of the laboratories regarding the accreditation process in different spheres, such as:

- quality and competence of the auditors [21];

- quality of the interpretation guides;

- accreditation process; and

- complaints procedure [22].

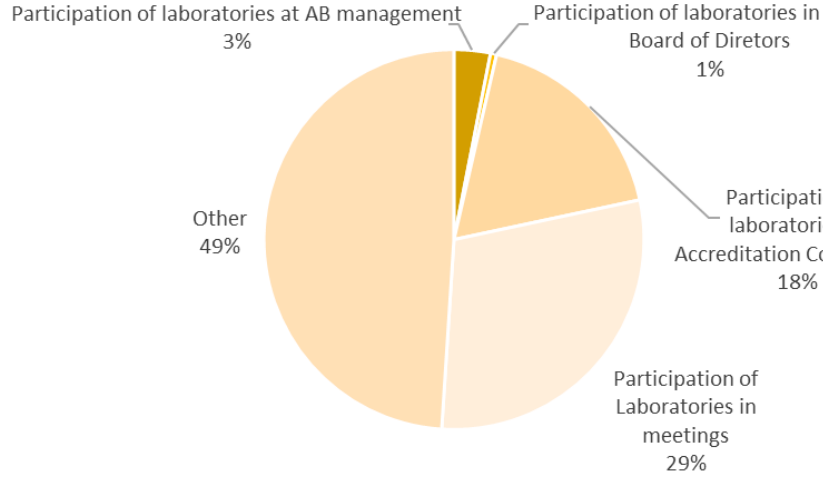

Figure 10. Distribution by type of participation in the definition of national accreditation strategy [18].

The first question addressed how laboratories perceive the lack of ILAC MRA as a trade barrier in its activity. The results show that about two thirds of the laboratories considered that this issue was not directly applicable to them, meaning that those laboratories do not carry out activities abroad. Considering only the remaining laboratories with activities abroad, $18 \%$ thereof felt that the lack of recognition of the ILAC MRA has impact on their activity.

Considering the improvement of the accreditation body's provided service, when questioned, the participants responded that the service was mostly unchanged from one year to the next or improved. Only $10 \%$ of the respondents indicated that the service provided by the accreditation body worsened. Still, there are big differences when the performance of accreditation bodies is compared worldwide. A more detailed analysis carried out for countries and economies with more than five responses shows, particularly in Europe, that the accreditation process has not improved from one year to the next, and there are even many responses stating that the process has worsened (Figure 11). However, in South and North America, Africa, and Asia, the process either remained the same or led to greater satisfaction.

For the different specific accreditation body performance aspects questioned, all received a positive evaluation. The best qualified are the 'quality of the auditors' and 'the reporting of the assessment' (Figure 12). At the other end are the aspects related to the laboratories' interaction with the accreditation bodies, namely the way in which the accreditation body deals with the complaints, how it adapts procedures to the laboratories' different business needs, and how the accreditation body promotes the accreditation.

The final set of questions look at the aspects considered most positive and identifies the aspects of the accreditation process that need improvement; the classification obtained is presented

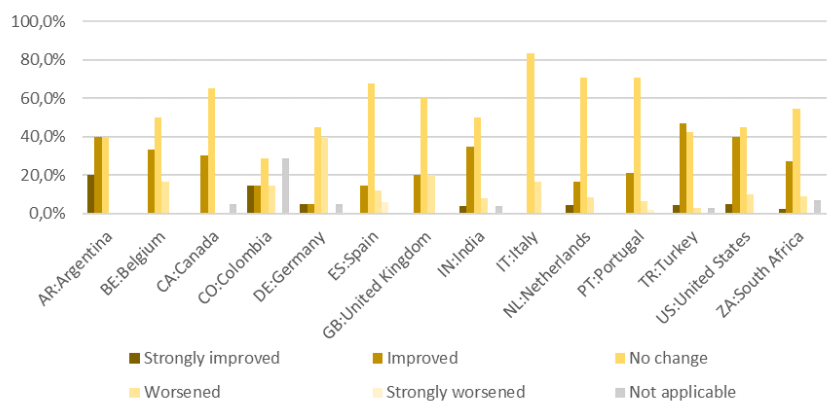

Figure 11. Comparison of accreditation services with the previous year, by country (countries with five or more answers) [18]. 


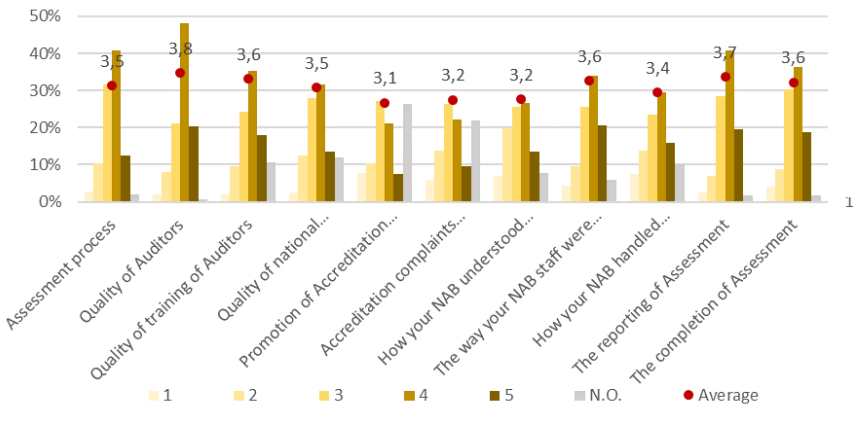

Figure 12. Satisfation with different accreditation aspects [18].

in Figure 13 and Figure 14. In line with the results presented previously, Figure 13 shows that the major aspects that need improvement by accreditation bodies are the public promotion of the added value of accreditation that leads to a better cost benefit for the organisations. Furthermore, the interpretation of the ISO / IEC 17025 requirements that are transposed to national interpretation guides is a parameter that should be the subject of additional research.

The quality of the assessment, in line with the answers about the quality of the auditors, is the top-rated aspect of the accreditation procedure (Figure 14). Also noteworthy is the cycle and frequency of assessment, but a more careful analysis is necessary in this parameter in order to identify the countries and economies to which this response applies.

A final important aspect considered in the survey was whether the laboratories were comfortable filling a complaint or appeal of the accreditation process with your accreditation body and not be concerned about reprisal. About one third of the laboratories $(34 \%)$ answered that they are not comfortable of filing a complaint, mainly because they believe the complaint will not alter any $\mathrm{AB}$ operating procedure

\section{CONCLUSIONS AND OUTLOOK}

Accreditation plays a fundamental role in the economy and is expected to be an engine of economic development on a fair trade basis [23], [24]. In order to achieve this objective, it is necessary to ensure that the application and assessment of the standard requirements of ISO/IEC 17025 (the reference standard for laboratory accreditation) is applied worldwide in a balanced, harmonised, and consistent manner.

Nowadays, on the edge of a new industrial revolution, Industrialisation 4.0, 'the response to it must be integrated and comprehensive, involving all stakeholders of the global polity, from the public and private sectors to academia and civil society' [25]. The collaboration of the laboratory community for this purpose is necessary, and the role of entities such as ILAC LC is particularly relevant, as demonstrated by the action of promoting a survey to this community in order to understand the current state of implementation of accreditation as well as its positive aspects and opportunities for improvement.

It is also known that 'the conformity assessment community including accreditation bodies is a conservative community' [25], which reinforces the importance of and need for the diagnosis provided by this survey, pointing out the main factors that the community feels are the most urgent ones to change.

This approach has also enabled an independent evaluation of NABs' performance as a way of supporting the evolution of accreditation and its recognition in the international context.

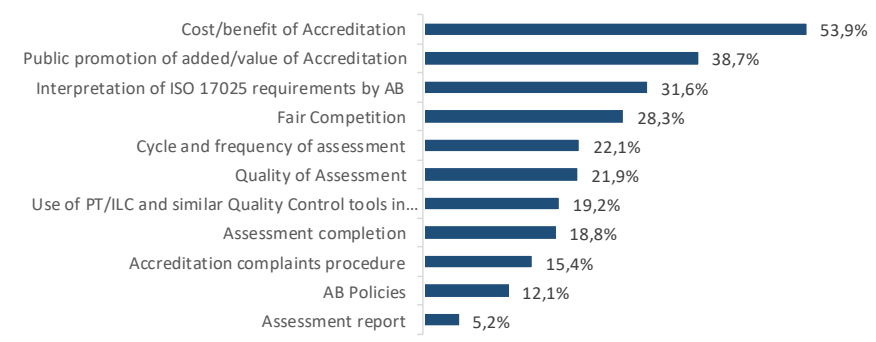

Figure 13. Distribution of replies by types of activities [18].

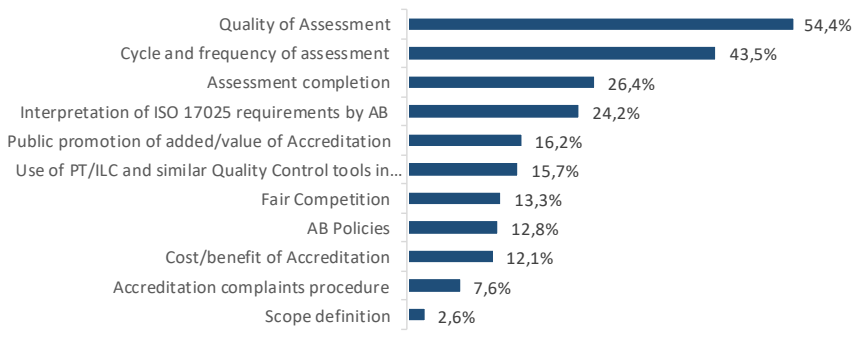

Figure 14. Best performance aspect of accreditation in countries and economies [18].

\section{ACKNOWLEDGEMENTS}

To the members of ILAC Laboratory Committee, the coauthors of the report '2017 International Survey on Harmonisation and Consistency of Accreditation: A Global View of Laboratories and Conformity Assessment Bodies Concerns, Expectations, and Challenges'.

To the laboratories and other stakeholders; national and international laboratory and conformity assessment bodies; and associations and international organisations that supported and contributed for this study.

\section{REFERENCES}

[1] M. Frenz, R. Lambert, The Economics of Accreditation, United Kingdom Accreditation Service (UKAS), March 2013.

[2] Quality Infrastructure 2017 definition, INetQI, adopted by BIPM, IAF, IEC, ILAC, ISO, ITC, ITU, OIML, UNECE, UNIDO, and the World Bank.

[3] ISO/IEC 17025:2017, General Requirements for the Competence of Testing and Calibration Laboratories, ISO, Geneva, Switzerland.

[4] ISO/IEC 17020:2012, Conformity Assessment - Requirements for the Operation of Various Types of Bodies Performing Inspection, ISO, Geneva, Switzerland, 2012.

[5] ISO/IEC 17025, General Requirements for the Competence of Testing and Calibration Laboratories, ISO, Geneva, Switzerland, 2017.

[6] ISO/IEC 17025:2017 Handbook, EUROLAB aisbl, Brussels, Belgium, 2018.

[7] K. Lawrence, Developing Leaders in a VUCA Environment, UNC Kenan-Flagler Business School, Chapel Hill, NC, USA. 2013.

[8] Deloitte Developments LLC, Tech Trends 2019: Beyond the Digital Frontier, Deloitte Insights, 2019.

[9] A Digital Single Market Strategy for Europe. Communication from the Commission to the European Parliament, the Council, the European Economic and Social Committee, and the Committee of the Regions, Brussels, Belgium, 6 May 2015.

[10] European Commission, European Commission Digital Strategy A Digitally Transformed, User-Focused and Data-Driven Commission, Brussels, Belgium, 21 November 2018. 
[11] Deloitte, Smart Cities - How Rapid Advances in Technology Are Reshaping Our Economy and Society, Deloitte Report, Ver. 1.0, November 2015.

[12] European Commission, Digital Agenda for the EU - Digital Transition Action Plan, Brussels, Belgium, 28 June 2018.

[13] F. Gaub, Global Trends to 2030 - Challenges and Choices for Europe, European Strategy and Policy Analysis System, European Union Project, 2019.

[14] IAF/ILAC B5.01/2018, Accreditation: Facilitation World Trade. ILAC-IAF Joint Publication, ILAC, Silverwater, Australia and IAF Chelsea, Canada, 2018.

[15] ISO 15189:2012, Medical Laboratories - Requirements for Quality and Competence, ISO, Geneva, Switzerland, 2012.

[16] ILAC B7:10/2015, The ILAC Mutual Recognition Arrangement. ILAC, Silverwater, Australia, 2015.

[17] CEOC International, White Paper: Trends \& Challenges for the Third Party TIC Sector, and Its Implications for CEOC International, Brussels, Belgium, September 2015.

[18] ILAC Laboratory Committee, 2017 International Survey on Harmonization and Consistency of Accreditation: A Global View of Laboratories and Conformity Assessment Bodies - Concerns, Expectations and Challenges, April 2018.

[19] ILAC G18:04/2010, Guideline for the Formulation of Scopes of Accreditation for Laboratories, ILAC, Silverwater, Australia, 2010.

[20] ILAC P9:06/2014, Policy for Participation in Proficiency Testing Activities. ILAC, Silverwater, Australia, 2010.

[21] ILAC G3:08/2012, Guidelines for Training Courses for Assessors Used by Accreditation Bodies, ILAC, Silverwater, Australia, 2012.

[22] ILAC R5:04/2016, ILAC Procedure for Handling Complaints, ILAC, Silverwater, Australia, 2016.

[23] ILAC-IAF, Accreditation: Adding Value to Supply Chains, ILACIAF Joint Publication, World Accreditation Day 2019, ILAC, Silverwater, Australia and IAF, Chelsea, Canada, 2018.

[24] UNIDO, Setting up Accreditation Bodies in Developing Economies: A Guide to Opening the Door for Global Trade (2 $2^{\text {nd }}$ Ed.), Vienna, Austria, 9 June 2017.

[25] M. M. Nilsson, Background Paper for Break-Out 1: Future Trends in Conformity Assessment and CASCO Standards in Industrialisation 4.0, ISO, Annex 2 to DEVCO 10/2019, July 2019. 